\title{
Effect of omalizumab as add-on therapy to Quality of Life Questionnaire for Korean Asthmatics (KAQLQ) in Korean patients with severe persistent allergic asthma
}

\author{
Jae-Woo Jung ${ }^{1,}$, Hae-Sim Park ${ }^{2,}$, Choon-Sik Park ${ }^{3}$, Sang-Heon Cho ${ }^{4}$, Inseon S. Choi ${ }^{5}$, Hee-Bom Moon ${ }^{6}$, \\ Soon Seog Kwon ${ }^{7}$, Ho Joo Yoon ${ }^{8}$, Jung Won Park ${ }^{9}$, Jong-Myung Lee ${ }^{10}$, Dong-Chull Choi ${ }^{11}$, and \\ Byoung Whui Choi ${ }^{1,12}$
}

\begin{abstract}
${ }^{1}$ Department of Internal Medicine, Chung-Ang University College of Medicine, Seoul; ${ }^{2}$ Department of Allergy and Clinical Immunology, Ajou University School of Medicine, Suwon; ${ }^{3}$ Department of Internal Medicine, Soonchunhyang University Bucheon Hospital, Bucheon; ${ }^{4}$ Department of Internal Medicine, Seoul National University College of Medicine, Seoul; ${ }^{5}$ Department of Internal Medicine, Chonnam National University Hospital, Gwangju; ${ }^{6}$ Department of Allergy and Clinical Immunology, Asan Medical Center, University of Ulsan College of Medicine, Seoul; ${ }^{7}$ Department of Internal Medicine, Bucheon St. Mary's Hospital, College of Medicine, The Catholic University of Korea, Bucheon; ${ }^{8}$ Department of Internal Medicine, Hanyang University College of Medicine, Seoul; ${ }^{9}$ Department of Internal Medicine, Yonsei University College of Medicine, Seoul; ${ }^{10}$ Department of Internal Medicine, School of Medicine, Kyungpook National University, Daegu; ${ }^{11}$ Division of Allergy, Department of Medicine, Samsung Medical Center, Sungkyunkwan University School of Medicine, Seoul; ${ }^{12}$ Department of Internal Medicine, Chung-Ang University H.C.S. Hyundae Hospital, Namyangju, Korea
\end{abstract}

Received: October 8, 2020 Revised : November 5, 2020 Accepted: November 16, 2020
Background/Aims: Omalizumab is the first biologic known to be effective in patients with severe allergic asthma.

Methods: This study was conducted as a multicenter, single-group, open trial to evaluate the improvement in the quality of life with the additional administration of omalizumab for 24 weeks in Korean patients with severe persistent allergic asthma.

Results: Of the 44 patients, $31.8 \%$ were men and the mean age was $49.8 \pm 11.8$ years. A score improvement of 0.5 points or more in the Quality of Life Questionnaire for Korean Asthmatics (KAQLQ) was noted in 50.0\% (22/44) of the patinets. In the improved group, the baseline total immunoglobulin E (IgE) level and the amount of omalizumab used were higher, and the day and night asthma symptoms were more severe, compared to those in the non-improved group. According to the Global Evaluation of Treatment Effectiveness, favorable outcomes were found in $78.6 \%$ of patients. The Korean asthma control test $(p<0.005)$ and forced expiratory volume in 1 second \% predicted $\left(\mathrm{FEV}_{1} \% ; p<0.01\right)$ improved significantly in patients who received omalizumab treatment, compared to that at week 0 , and the total dose of rescue systemic corticosteroids significantly decreased $(p<0.05)$. The improved group on KAQLQ showed a significant improvement in FEV1\% $(p<0.001)$. Conclusions: Omalizumab can be considered a biological treatment for Korean patients with severe allergic asthma. It is recommended to consider omalizumab as add-on therapy in patients with high baseline total IgE levels and severe asthma symptoms.

Keywords: Omalizumab; Quality of life; Republic of Korea; Asthma; Prospective studies

Correspondence to Byoung Whui Choi, M.D.

Department of Internal Medicine, Chung-Ang University H.C.S. Hyundae Hospital, 21 Bonghyeon-ro, Jinjeop-eup, Namyangju 12013, Korea, Tel: +82-31-574-9119,

Fax: +82-31-572-1194, E-mail: bwchoimd@cau.ac.kr, https://orcid.org/oooo-ooo1-7196-4075

*These authors contributed equally to this work. 


\section{INTRODUCTION}

With the development of drugs such as inhaled corticosteroids, $70 \%$ to $80 \%$ of patients with asthma can reach the goal of a "controlled state." However, in approximately $17 \%$ of patients, asthma is not well controlled even with stage 4 to 5 treatments of the Global Initiative for Asthma [1]. These cases are classified as difficult-to-treat asthma, and their treatment has recently attracted much attention. Some patients with difficult-to-treat asthma have inaccurate inhalation techniques, poor performance, and correctable factors such as smoking and other co-morbidities and can therefore be controlled with appropriate treatment or management $[2,3]$. However, approximately $1 / 4$ of difficult-to-treat asthma cases are not controlled despite the best appropriate treatment, correction of other contributing factors, and good patient performance. These are classified as severe asthma according to the Global Initiative for Asthma guidelines [1]. It was reported that severe asthma accounts for approximately $3 \%$ to $10 \%$ of all patients with asthma; however, it accounts for a very high proportion of medical expenses, owing to the cost of repeated hospitalizations and side effects due to the use of drugs such as systemic steroids. A Canadian study reported that severe asthma accounts for more than $60 \%$ of the total medical cost of asthma, resulting in an economic burden on families because of the reduced income and job restrictions due to the illness [4]. In a recent Korean study, the asthma-related prescription cost for severe asthma was 4 to 5 times higher than that of well-controlled asthma and 30 to 40 times higher than that of the intermittent treatment group [5].

With the recent development of various biologics, there has been remarkable progress in the treatment of severe asthma showing the type 2 inflammation phenotype [6-8]. These biologics are largely classified as anti-immunoglobulin $\mathrm{E}$ (anti-IgE), anti-interleukin-5/5 receptor, and anti-interleukin-4 receptor. The first recombinant, humanized, monoclonal IgG antibody developed against IgE, omalizumab, binds to circulating free $\operatorname{IgE}$ (rather than mast cells) with high affinity. Consequently, anti-IgE antibodies prevent free IgE from binding to the high-affinity IgE receptor (FceRI) on the surface of mast cells and basophils. Thus, even when exposed to causative allergens, mast cell activation does not occur and allergic symptoms are not caused. In addition, omalizumab treatment downregulates the FceRI receptors on the surface of mast cells and basophils [9].

Bronchial asthma is a chronic inflammatory disease in the airways. In particular, allergic asthma is an IgE-mediated disease characterized by exposure to allergens that cause chronic airway inflammation. Omalizumab, an anti-IgE antibody, is a breakthrough in the regulation of asthma that acts by blocking the initial stage of mast cell activation [10,11]. Since its development in 2001, omalizumab has been widely used in patients with relatively intractable and severe allergic asthma [12-18]. In Korea, omalizumab was approved for use in 2007 by the Ministry of Food and Drug Safety of South Korea and is recommended for use in patients with severe asthma. However, the Korean National Health Insurance has only covered omalizumab prescriptions since 2020. Therefore, it is more expensive than other general asthma drugs and has been prescribed for and used by less than $2 \%$ of patients with severe asthma $[19,20]$.

In a recent study, omalizumab showed varying results in the same severe perennial allergic asthma patient group [21]. Although many studies have been conducted to compare and predict the effect of omalizumab, there are no prospective studies targeting only the Korean population [20]. Differences regarding the heterogeneity of asthma between ethnicities should be confirmed, and studies on the effects of omalizumab and the characteristics of the treatment-responsive patient group in Korean patients with severe asthma are required.

Therefore, in the present study, we attempted to determine the effect of additional omalizumab treatment in Korean patients with severe allergic asthma that was not properly controlled with standard treatment.

\section{METHODS}

\section{Study design}

This study was conducted as a multicenter, single-group, open study to evaluate the improvement in the quality of life with the additional administration of omalizum$\mathrm{ab}$ in patients with severe persistent allergic asthma that had not been in a controlled status even with standard treatment. As a prospective study conducted over 24 weeks, patients were recruited from 11 university hos- 


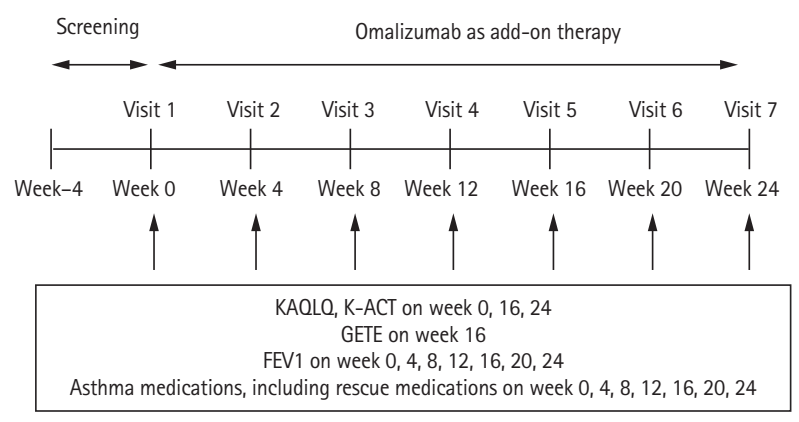

Figure 1. Study design. Patients visited seven times from baseline to 24 weeks at intervals of 4 weeks. Omalizumab treatment was administered through subcutaneous injection with the approved dosage schedule as additional therapy to the existing asthma treatment. Quality of life, asthma control, lung function, and use of asthma drugs were evaluated. KAQLQ, the Quality of Life Questionnaire for Adult Korean Asthmatics; K-ACT, Korean asthma control test; GETE, the global evaluation of treatment effectiveness; $\mathrm{FEV} 1$, forced expiratory volume in 1 second.

pitals in Korea.

There were seven patient visits from baseline to 24 weeks at 4-week intervals, and the quality of life, asthma control, lung function, and use of asthma medications in patients were evaluated (Fig. 1). The study was conducted from February 15, 2008 to July 1, 2009.

Omalizumab treatment was administered through subcutaneous injection in accordance with the approved dosage table as additional therapy to the existing asthma treatment. All patients received omalizumab injections until the last scheduled visit (week 24), regardless of the treatment response. Patients were allowed to adjust their concomitant asthma medications to the extent that they did not worsen symptoms, and rescue medications were also used as needed.

Informed consent was obtained from each patient. This study was approved by the Institutional Review Board of each hospital (Chung-Ang University Hospital IRB no. 2008-002-01).

\section{Patients}

Patients with severe persistent allergic asthma aged 12 to 75 years were enrolled. Allergic asthma patients were defined as patients with positive responses to at least one perennial allergen (e.g., house dust mites or animal dander) on the skin prick test and/or in vitro test and whose forced expiratory volume in 1 second $\%$ predicted
(FEV $1 \%$ ) increased by $>12 \%$ and $>200 \mathrm{~mL}$ compared to that at the baseline within 30 minutes after the inhalation of salbutamol $(200 \mu \mathrm{g})[1]$.

The definition of severe persistent asthma was as follows: despite regular use of high-dose inhaled corticosteroids (ICS) and long-acting $\beta 2$-agonist (LABA), asthma exacerbations requiring systemic corticosteroids occurred at least twice in the past 12 months or a case of continuous use of the oral corticosteroid (OCS), prednisolone at $5 \mathrm{mg}$ or more per day for 12 months as maintenance therapy. In addition, patients with $\mathrm{FEV}_{1} \%$ of $\geq$ $40 \%$ and $\leq 80 \%$ were enrolled. High-dose ICS was defined as beclomethasone dipropionate as an ICS of 1,000 to $2,000 \mu \mathrm{g} /$ day or more or equivalent $(\geq 800$ to $1,600 \mu \mathrm{g} /$ day budesonide, $\geq 500$ to $1,000 \mu \mathrm{g} /$ day fluticasone).

The patients also had to have a total serum IgE level of 30 to $700 \mathrm{IU} / \mathrm{mL}$ and a body weight of $150 \mathrm{~kg}$ or less to meet the suitability criteria of the omalizumab dosage form.

Exclusion criteria were: (1) pregnant or nursing women, (2) patients who had been administered omalizumab in the past, (3) patients who cannot complete the questionnaire or cannot comply with the requirements of the study, (4) from the perspective of the researcher, patients who had another concurrent disease or severe medical condition, (5) patients who had been treated for asthma exacerbation within 4 weeks before participation in the study, and (6) patients with a smoking history of 10 pack-years or more.

\section{Primary endpoint}

To evaluate the primary endpoint, the quality of life was measured using the Quality of Life Questionnaire for Adult Korean Asthmatics (KAQLQ), modified and verified in Korea. It comprises four areas and a total of 17 items (six symptoms, five activities, three emotions, and three environments), with higher scores indicating a higher quality of life. The average KAQLQ score was measured for all four areas at weeks 0,16 , and 24 [22]. The change was measured at week 24 in comparison with that at week $\mathrm{o}$, and a case of improvement by 0.5 points or more was defined as "improvement" this was designated as the primary endpoint. Patients corresponding to this improvement in KAQLQ were classified into the improved group and the others into the non-improved group. 


\section{Secondary outcome}

Secondary endpoints included the global evaluation of treatment effectiveness (GETE), Korean asthma control test (K-ACT), lung function, use of oral steroids, and changes in the use of other asthma medications. Medical staff conducted the GETE at week 16 and evaluated the patients' response to omalizumab treatment in five stages: excellent, good, moderate, poor, and worsening. Among these, patients with excellent and good responses were classified as the favorable group, and those with moderate, poor, and worsening asthma were classified as the unfavorable group. The degree of asthma control was confirmed using K-ACT at weeks o, 16, and 24. To calculate the total K-ACT score, those with less than 20 points were evaluated as "uncontrolled," 20 to 24 points as "partly controlled," and 25 points as "controlled." The lung functions, FEV1 and FEV1\%, were measured at each visit. ICS-LABA, leukotriene receptor antagonists, OCS doses used as maintenance therapy, and concomitant medications such as rescue systemic corticosteroids, anticholinergics, and short-acting $\beta 2$-agonists were checked at each visit.

\section{Drug safety evaluation}

To evaluate the safety of omalizumab, the adverse events (AEs), serious adverse events (SAEs), and adverse drug reactions (ADRs) that developed after omalizumab administration were investigated.

\section{Statistical analysis}

The results were analyzed using SPSS version 16.0 (SPSS Inc., Chicago, IL, USA). Two-tailed analyses were conducted, and $p$ values $<0.05$ were considered significant. Continuous data are expressed as the mean \pm standard deviation (SD), and categorical data are expressed as numbers and percentages. In the figures, data are expressed as the mean \pm standard error of the mean (SEM). For statistical analysis, intra-group changes such as those in KAQLQ, K-ACT, and FEV1\% and FEV 1 (mL) were compared using a paired $t$ test, and differences between groups were compared using the Mann-Whitney test. The improved and non-improved groups were classified using the KAQLQ results and analyzed using a chi-squared or Fisher's exact test and a Mann-Whitney test to determine whether there was a difference in baseline characteristics between the two groups. A p value <
0.5 was considered statistically significant.

\section{RESULTS}

\section{Characteristics of the study patients}

The patients $(n=54)$ enrolled in this clinical trial received omalizumab and were evaluated for safety at least once. Among them, three patients who had not been subjected to the primary efficacy evaluation, four patients who did not meet the selection/exclusion criteria, one patient who violated the usage and dosage, one patient who had adverse reactions, one patient who had tracking failure, and one patient who had no effects were excluded. Thus, the effect of omalizumab was evaluated in 44 patients who completed the study according to the clinical trial protocol.

Of the 44 patients, $31.8 \%$ were male, and the mean age was $49.8 \pm 11.8$ years (Table 1). Perennial allergic rhinitis was the most common co-morbid allergic disease and was found in 37 (84.1\%) patients, followed by allergic conjunctivitis $(12 / 44,27.3 \%)$ and urticaria $(5 / 44,11.4 \%)$. The mean serum total IgE level was $212.0 \pm 163.6 \mathrm{IU} / \mathrm{mL}$, and mean $\mathrm{FEV} 1 \%$ was $62.2 \% \pm 1.8 \%$. As for causal allergens, all patients were allergic to one or more perennial allergens, and $36.5 \%$ of patients had positive responses to pollen.

When evaluating the asthma medication they used for the past 4 weeks before enrollment, all 44 patients received fixed dose combination therapy, and the average daily use of ICS as an equivalent dose of beclomethasone dipropionate was $1,302.27 \pm 526.28 \mu \mathrm{g}$. There were 13 patients $(29.5 \%)$ taking oral corticosteroids daily as maintenance therapy, and their average daily dose as an equivalent dose of prednisolone was $8.1 \pm 4.7 \mathrm{mg}$. There were 15 patients (34.1\%) who took rescue OCS for the past 4 weeks before enrollment, and the total dose was 105.9 $\pm 124.3 \mathrm{mg}$ as predniosolone. The average dose of omalizumab administered in 1 month was $346.0 \pm 188.8 \mathrm{mg}$.

\section{Primary endpoint}

KAQLQ

Analysis of the change in week 24 in comparison with week o for KAQLQ indicated an improvement, with an increase of 0.5 points or more in the KAQLQ in 22/44 pa- 
Table 1. Patient demographic and clinical characteristics at baseline $(n=44)$

\begin{tabular}{|c|c|}
\hline Characteristic & Value \\
\hline Age, yr & $49.8 \pm 11.8$ \\
\hline Male sex & $14(31.8)$ \\
\hline Weight, kg & $63.5 \pm 11.1$ \\
\hline Height, cm & $162.1 \pm 7.8$ \\
\hline \multicolumn{2}{|l|}{ Smoking status } \\
\hline Never & $34(77 \cdot 3)$ \\
\hline Ex-smoker & $9(20.5)$ \\
\hline Current smoker & $1(2.3)$ \\
\hline \multicolumn{2}{|l|}{ Concomitant allergic disease } \\
\hline Perennial allergic rhinitis & $37(84.1)$ \\
\hline Allergic conjunctivitis & $12(27 \cdot 3)$ \\
\hline Urticaria & $13(19 \cdot 5)$ \\
\hline Blood white blood cell counts, $\mathrm{K} / \mu \mathrm{L}$ & $8.5 \pm 4.1$ \\
\hline Blood eosinophils, \% & $5.6 \pm 8.3$ \\
\hline Total IgE, IU/mL & $212.0 \pm 163.6$ \\
\hline \multicolumn{2}{|l|}{ Pulmonary function test } \\
\hline $\mathrm{FEV} 1, \mathrm{~mL}$ & $1,745 \cdot 9 \pm 84.6$ \\
\hline $\mathrm{FEV} 1 \%$ & $62.2 \pm 1.8$ \\
\hline \multicolumn{2}{|l|}{ Allergens } \\
\hline Perennial aeroallergens & $44(100)$ \\
\hline Seasonal aeroallergens & $16(36.5)$ \\
\hline \multicolumn{2}{|l|}{ Asthma clinical symptoms } \\
\hline \multicolumn{2}{|l|}{ Morning symptoms } \\
\hline No symptoms at all; unrestricted activity & $21(47.7)$ \\
\hline Symptoms caused little or no discomfort; unrestricted activity & $5(11.4)$ \\
\hline Symptoms caused some discomfort; sometimes limiting strenuous activity & $14(31.8)$ \\
\hline Symptoms caused moderate discomfort and at limited routine activity & $3(6.8)$ \\
\hline Symptoms occurred at rest, caused marked discomfort, and usually limited routine activity & $1(2.3)$ \\
\hline \multicolumn{2}{|l|}{ Night time symptoms } \\
\hline Patient did not wake up & $27(61.4)$ \\
\hline Patient awoke once, but did not use rescue medication & $12(27 \cdot 3)$ \\
\hline Patient awoke once, but their rescue medication controlled the symptoms & $4(9.1)$ \\
\hline Patient awoke more than once, but their rescue medication controlled the symptoms & $1(2.3)$ \\
\hline Patient had difficulty sleeping even though he/she used rescue medication & O \\
\hline \multicolumn{2}{|l|}{ Dose of asthma medication } \\
\hline \multicolumn{2}{|l|}{ Fixed dose combination therapy $(n=44)$} \\
\hline Inhaled corticosteroids/day, $\mu \mathrm{g}^{\mathrm{a}}$ & $1,302.3 \pm 526.3$ \\
\hline Long-acting $\beta 2$ agonist/day, $\mu \mathrm{g}$ & $73 \cdot 3 \pm 47 \cdot 6$ \\
\hline Anticholinergics/day, $\mu \mathrm{g}(\mathrm{n}=12)$ & $243.9 \pm 578.0$ \\
\hline Leukotriene inhibitors/day, mg $(n=41)$ & $124.6 \pm 190.7$ \\
\hline Oral corticosteroids maintenance/day, $\mathrm{mg}(\mathrm{n}=13)^{\mathrm{b}}$ & $8.1 \pm 4.7$ \\
\hline Rescue oral corticosteroids/4 weeks, mg $(\mathrm{n}=15)^{\mathrm{b}}$ & $105 \cdot 9 \pm 124 \cdot 3$ \\
\hline Rescue short-acting $\beta 2$ agonist/4 weeks, $\mu \mathrm{g}(\mathrm{n}=14)^{\mathrm{c}}$ & $2,927.3 \pm 3,755.8$ \\
\hline Mean omalizumab dose per month, mg & $346.0 \pm 188.8$ \\
\hline
\end{tabular}

Values are presented as number (\%) or mean \pm standard deviation.

IgE, immunoglobulin E; FEV1, forced expiratory volume in 1 second; FEV1\%, forced expiratory volume in 1 second.

${ }^{\mathrm{a}}$ Equivalent dose of beclometasone dipropionate.

${ }^{\mathrm{b}}$ Equivalent dose of prednisolone.

${ }^{\mathrm{c}}$ Salbutamol. 


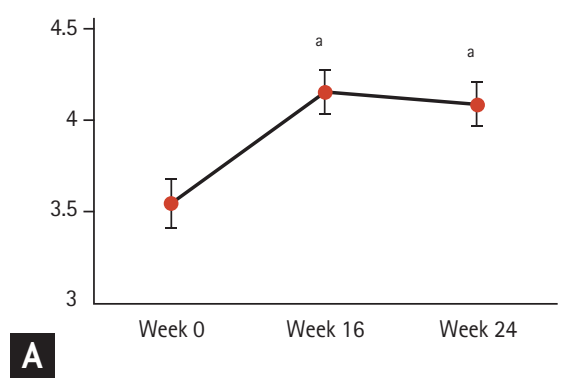

A

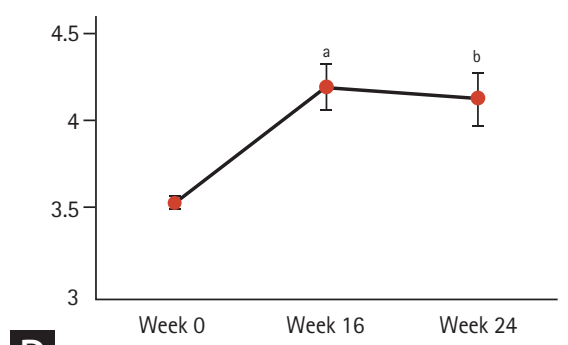

D

Figure 2. Mean \pm standard error of the mean the Quality of Life Questionnaire for Adult Korean Asthmatics (KAQLQ). (A) KAQLQ (total), (B) KAQLQ (symptom), (C) KAQLQ (activity), (D) KAQLQ (emotion), (E) KAQLQ (environment). KAQLQ at week 16 and week 24 showed improvement not only in the total score but also in each score in the symptom, activity, emotion, and environment aspects compared to the baseline KAQLQ. ${ }^{a} p<0.001,{ }^{b} p<0.005$ compared to KAQLQ at week o.

tients (50.0\%). The KAQLQ results between weeks o, 16, and 24 were compared. The mean KAQLQ for each time point was $3.6 \pm 0.9$ at week $0,4.2 \pm 0.8$ at week 16 , and 4.1 \pm 0.8 at week 24 , and the difference was statistically significant between week 16 and week 24 compared to week $\circ(p<0.001$ and $p<0.001$, respectively) (Fig. $2 \mathrm{~A})$. There was no significant difference between weeks 16 and 24 .

Considering the individual KAQLQ aspects, the scores of each item at week o, week 16 , and week 24 were $3.4 \pm 0.9,4.0 \pm 0.1(p<0.001)$, and $4.0 \pm 0.8(p<0.001)$, respectively, for the symptom items; $3.6 \pm 0.9,4.2 \pm 0.7$ $(p<0.001)$, and $4.13 \pm 0.9(p=0.001)$, respectively, for the activity items; $3.6 \pm 0.2,4.2 \pm 0.9(p<0.001)$, and $4.1 \pm 1.0$ $(p=0.002)$, respectively, for the emotion category; and $3.7 \pm 1.0,4.3 \pm 0.8(p<0.001)$, and $4.2 \pm 0.8(p<0.001)$, respectively, for the environment category, all showing statistically significant differences compared to week o (Fig. 2B-2E).

\section{Secondary endpoints}

GETE

The GETE conducted at week 16 resulted in $14.3 \%$ patients having an excellent rating (6/42), $64.3 \%$ of patients having a good rating (27/42), 19.0\% of patients having a moderate rating (8/42), and $2.4 \%$ of patients having a poor rating $(1 / 42)$. Patients were classified into favorable and unfavorable groups according to their GETE results. The favorable group comprised $78.6 \%$ of patients (33/42), whereas the unfavorable group comprised $21.4 \%$ (9/42).

\section{K-ACT}

The mean K-ACT score at each visit was $18.09 \pm 4.8$ at week $0,21.18 \pm 4.2$ at week 16 , and $20.48 \pm 4.4$ at week 24. Compared with the K-ACT at week o, the K-ACT at weeks 16 and 24 showed statistically significant differences $(p<0.001$ and $p=0.001$, respectively) (Fig. 3A). There was no significant difference between weeks 16 and 24 .

When the K-ACT scores were divided across three groups (uncontrolled/partly controlled/controlled sta- 


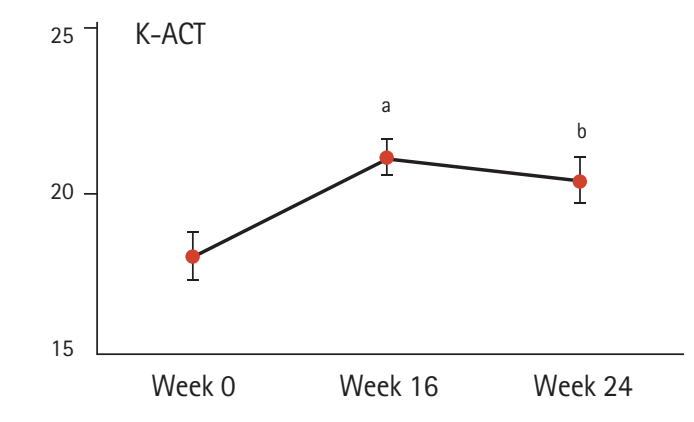

A

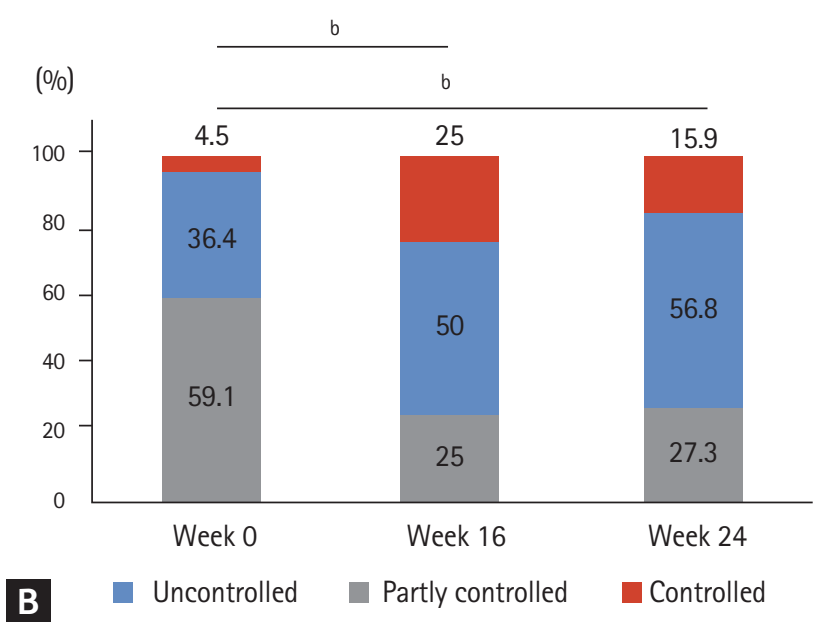

B

Figure 3. Korean asthma control test (K-ACT) at week o, 16, and 24. (A) Mean \pm standard error of the mean K-ACT. (B) Asthma control levels. K-ACT was improved after omalizumab treatment, and the proportions of "partly controlled" and "controlled" on week 16 and week 24 were higher than those at week $0 .{ }^{a} p<0.001,{ }^{b} p<0.005$ compared to K-ACT at week 0.

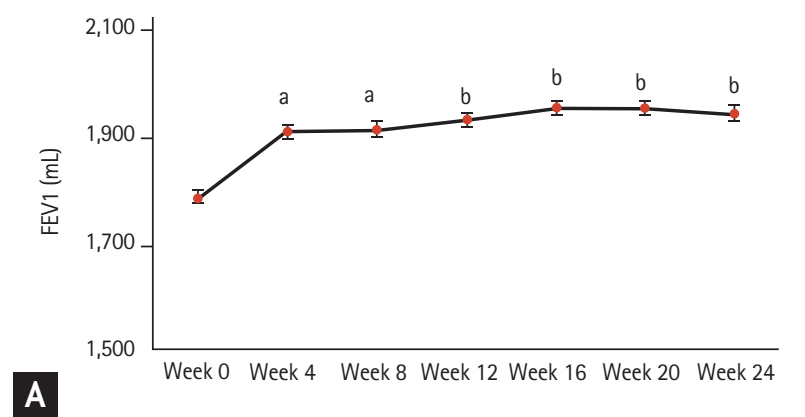

B

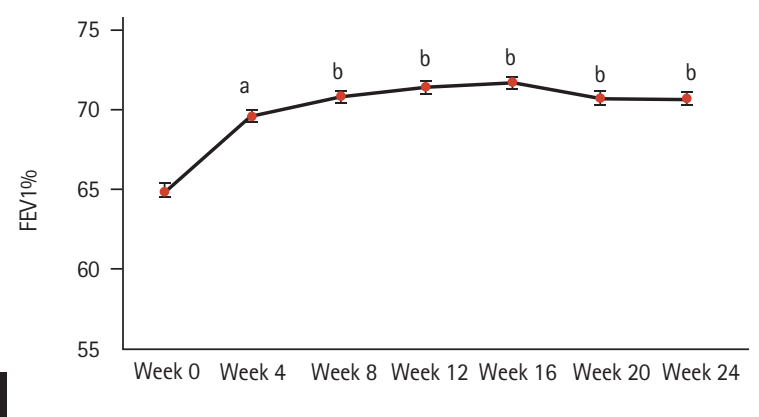

Figure 4. Mean \pm standard error of the mean forced expiratory volume in 1 second (FEV1). (A) FEV1, (B) FEV1\%. In the pulmonary function tests performed every 4 weeks, FEV1 and FEV1\% improved compared to baseline pulmonary function, and the effect was observed from 4 weeks of omalizumab treatment. ${ }^{a} p<0.5,{ }^{b} p<0.05$ compared to FEV1 at week 0.

tus), the proportions observed were 59.1\%/36.4\%/4.5\% at week $0,25.0 \% / 50.0 \% / 25.0 \%$ at week 16 , and $27.3 \% / 56.8 \% / 15.9 \%$ at week 24 , respectively. When the asthma control level at week 24 was compared to that at week o, the proportion of the "uncontrolled" status was lower, whereas that of "partly controlled" and "controlled" was higher, overall indicating an improved asthma control status $(p=0.001$ and $p=0.007$, respectively) (Fig. 3B).

\section{Lung function}

The mean FEV1 $(\mathrm{mL})$ was 1,789.6 \pm 536.4 at week o, 1,911.3 \pm 536.4 at week $4(p=0.026), 1,915.7 \pm 96.2$ at week $8(p=$ 0.013), $1,933.9 \pm 549.2$ at week $12(p=0.001), 1,957.4 \pm 555.7$ at week $16(p=0.002), 1,956.1 \pm 95.9$ at week $20(p=0.004)$, and $1,946.3 \pm 662.5$ at week $24(p=0.003)$, showing significant differences compared to the baseline FEV1 $(\mathrm{mL})$ at week o (Fig. 4A).

The mean values of $\mathrm{FEV} 1 \%$ were $65.0 \% \pm 12.6 \%$ at week $0,69.6 \% \pm 2.3 \%$ at week $4(p=0.006), 70.8 \pm 2.2$ at week $8(p$ $=0.001), 71.4 \pm 2.3$ at week $12(p=0.001), 71.7 \pm 15.1$ at week $16(p=0.001), 71.2 \pm 2.4$ at week $20(p=0.004)$, and $70.7 \pm$ 17.2 at week $24(p=0.004)$, showing significant differences compared to the baseline value of $\mathrm{FEV}_{1} \%$ at week o (Fig. 4B). FEV1\% showed no difference at 4, 8, 12, 16, 20, and 24 weeks.

FEV1 (mL) and FEV1\% were significantly improved from week 4 of treatment and were maintained from week 12 to week 24 . 

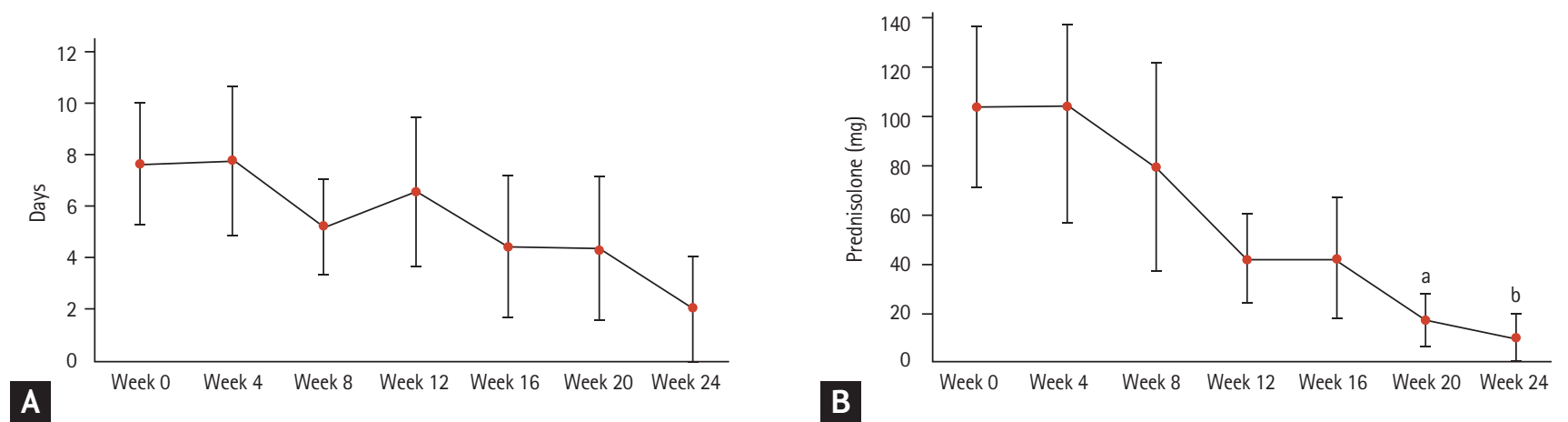

Figure 5. Rescue systemic corticosteroid use during the past 4 weeks before patient enrollment. (A) Duration of rescue oral corticosteroid (OCS) use. (B) Dose of rescue OCS. During the treatment period of omalizumab, the duration of rescue systemic corticosteroid use did not change, but the total dose showed a significant decrease. ${ }^{\mathrm{a}} \mathrm{p}<0.05,{ }^{\mathrm{b}} \mathrm{p}<0.01$ compared to rescue OCS use at week $\mathrm{O}$.

\section{Asthma concomitant medications}

Considering the daily dose of using OCS as maintenance therapy, 13 patients took OCS as maintenance therapy at week $\mathrm{O}$, with an average daily dose of $8.1 \pm 4.7 \mathrm{mg}$. The dosage of OCS maintenance was $8.5 \pm 5.1 \mathrm{mg}$ at week 16 and $9.4 \pm 4.4 \mathrm{mg}$ at week 24 , showing no significant differences compared to that at week o $(p=0.203)$.

The number of days and total dosage of rescue systemic corticosteroids during the 4 weeks before enrollment were also analyzed. As of week o, 15 patients took OCS as rescue medication during that period, with a mean total OCS dosage of $105.9 \pm 124.3 \mathrm{mg}$, and they took rescue OCS for $7.7 \pm 9.0$ days (Fig. 5). The mean total OCS dosage of 15 patients decreased to $17.9 \pm 40.1 \mathrm{mg}$ for 4.4 \pm 10.5 days at week 20 and $10.8 \pm 38.6 \mathrm{mg}$ for $2.1 \pm 7.7$ days at week 24. Compared to week o, there were no statistically significant differences in the number of days; however, the average dose was significantly decreased at week $20(p=0.024)$ and week $24(p=0.005)$. We examined the proportion of patients who reduced OCS use by $50 \%$ or more at week 24 compared to that in week o. In the case of maintenance therapy, none of the patients corresponded to this criterion, but $60 \%$ (9/15) of the patients who took OCS as rescue medication did so, suggesting that the frequency of asthma exacerbation decreased with the addition of omalizumab in the present study. When we compared the use of other drugs at week 24 to that at week $\mathrm{o}$, there were no significant differences in the average daily dose of ICS ( $\mathrm{n}=44 ; 1,244.0 \pm 545.1 \mu \mathrm{g}$ vs. $1,302.3 \pm 526.3 \mu \mathrm{g}, p=0.342), \mathrm{LABA}(\mathrm{n}=44 ; 80.7 \pm 73.5 \mu \mathrm{g}$ vs. $73.3 \pm 47.6 \mu \mathrm{g}, p=0.299)$, leukotriene receptor antagonists
( $\mathrm{n}=41 ; 99.6 \pm 177.9 \mathrm{mg}$ vs. $124.6 \pm 190.7 \mathrm{mg}, \mathrm{p}=0.137$ ), short-acting $\beta 2$-agonists $(\mathrm{n}=14 ; 554.6 \pm 542.9 \mu \mathrm{g}$ vs. $2,927.3$ $\pm 3,755.8 \mu \mathrm{g}, \mathrm{p}=0.073)$, and anticholinergics $(\mathrm{n}=12 ; 1,727.2$ $\pm 5,157.2 \mu \mathrm{g}$ vs. $243.9 \pm 578.0 \mu \mathrm{g}, p=0.344)$.

\section{Predictable factors for improvements in KAQLQ}

Statistical analysis was performed to determine whether there are baseline characteristics that can predict meaningful improvements in the quality of life (KAQLQ) through omalizumab treatment in patients with severe asthma (Table 2). There were no differences in age, sex, baseline FEV1, and blood eosinophils between the improved and non-improved groups. The baseline total IgE levels of the improved group were significantly higher than those of the non-improved group (270.5 \pm $187.1 \mathrm{IU} / \mathrm{mL}$ vs. $153.4 \pm 11.23 \mathrm{IU} / \mathrm{mL}, p=0.017)$. Accordingly, the monthly dose of omalizumab used was significantly higher (409.1 $\pm 191.9 \mathrm{mg}$ vs. $283.0 \pm 166.8 \mathrm{mg}, p=0.025$ ). In the baseline asthma clinical symptoms, the improved group showed more severe asthma symptoms both in the morning and at night than the non-improved group ( $p=0.002$ and $p=0.049$, respectively).

\section{Changes in lung functions according to the KAQLQ and GETE scores}

The differences in $\mathrm{FEV}_{1} \%$ between the improved and non-improved groups according to the KAQLQ results were analyzed (Fig. 6A). The mean value of FEV1\% was $66.9 \pm 10.8$ in the improved group and $63.0 \pm 14.2$ in the non-improved group at week o, but the difference was not significant $(p=0.307)$. However, at week 24, there was 

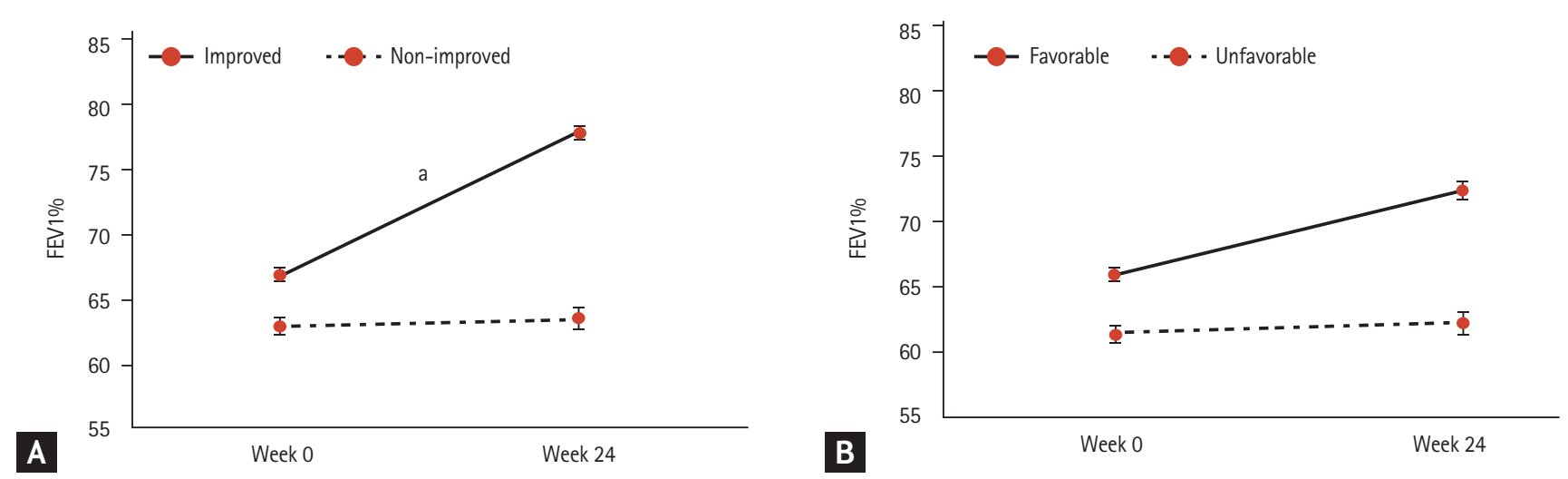

Figure 6. Changes in lung function according to the Quality of Life Questionnaire for Adult Korean Asthmatics (KAQLQ) and the global evaluation of treatment effectiveness (GETE). (A) Forced expiratory volume in 1 second \% predicted (FEV1\%) at week $\mathrm{O}$ and week 24 according to the KAQLQ results. (B) FEV1\% at week o and week 24 according to the GETE results. The "improvement" group of KAQLQ showed a significant improvement in FEV1\% compared to the "non-improvement" group, but in the case of GETE, there was no difference in FEV1\% between the "favorable" group and the "unfavorable" group. ${ }^{a} p<0.001$ compared to $\mathrm{FEV}_{1} \%$ at week o.

a significant difference in $\mathrm{FEV} 1 \%$ between the improved and non-improved groups $(78.0 \% \pm 12.1 \%$ vs. $63.5 \% \pm$ $4.0 \%, p=0.004)$.

Based on GETE, the difference in FEV1\% between the favorable and unfavorable groups was analyzed (Fig. 6B). FEV $1 \%$ was $66.0 \% \pm 12.6 \%$ in the favorable group and $61.6 \% \pm 13.5 \%$ in the unfavorable group at week $\mathrm{O}$ and $72.6 \% \pm 18.5 \%$ in the favorable group and $62.3 \% \pm 10.5 \%$ in the unfavorable group at week 24 . There were no differences in $\mathrm{FEV}_{1} \%$ between the two groups at weeks o and $24(p=0.369$ and $p=0.122$, respectively).

\section{Safety}

During the study period, 51 patients were evaluated for safety, excluding three patients for whom the primary efficacy evaluation was not performed.

There were $29 \mathrm{AEs}$ in 19 patients (37.3\%), three SAEs in three patients (5.9\%), and six ADRs in three patients (5.9\%). The most frequent $\mathrm{AE}$ was upper respiratory tract infection (four cases), followed by rhinitis (two cases), and dyspnea (two cases). The three cases of SAEs were asthma exacerbation, eosinophilia, and road traffic accident.

As for the ADRs related to omalizumab, thirst, dizziness, nausea, and swelling occurred in one patient; dyspnea occurred in one patient; and eosinophilia occurred in one patient. Eosinophilia is a serious ADR that may be associated with omalizumab because it recovered after administration was stopped.

\section{DISCUSSION}

This study is the first prospective study in Korea to observe the effect of omalizumab in patients over 12 years of age with severe persistent allergic asthma that had not been controlled with standard treatment. In Koreans with severe asthma, their quality of life improved after additional treatment with omalizumab; their asthma symptoms, asthma control status, and lung function improved; and the use of rescue OCS also decreased. In addition, the ADRs caused by the use of omalizumab were not generally observed in the Korean population.

Considering the development of various biologics that can be used in severe asthma, further research is still needed to determine which biologics are more effective for specific patient subgroups [6,23-28]. Omalizumab is relatively inexpensive compared to other biologics, and there have been reports that it is effective in non-atopic asthma patients [29-32]. In this study, additional treatment with omalizumab resulted in an average increase of 0.6 points in the KAQLQ score after the start of treatment, showing a statistically significant improvement, which was similar to that reported in previous studies $[11,17,18]$. In the KAQLQ, 22 patients (50\%) showed an improvement of 0.5 points or more, which can be considered a minimal difference. However, in the study conducted by Buhl et al. [11] and the INvestigatioN of Omalizumab in seVere Asthma TreEatment (INNOVATE) study [17], which are representative omalizumab 
Table 2. Baseline characteristics according to KAQLQ results

\begin{tabular}{|c|c|c|c|}
\hline Characteristic & $\begin{array}{l}\text { Improved group } \\
\quad(\mathrm{n}=22)\end{array}$ & $\begin{array}{l}\text { Non-improved } \\
\text { group }(\mathrm{n}=22)\end{array}$ & $p$ value \\
\hline Age, yr & $49 \cdot 3 \pm 10.1$ & $50.3 \pm 13.5$ & 0.782 \\
\hline Male sex & $8(36.4)$ & $6(27 \cdot 3)$ & 0.517 \\
\hline Weight, kg & $62.4 \pm 11.7$ & $64.6 \pm 10.6$ & 0.515 \\
\hline Height, cm & $162.3 \pm 8.1$ & $161.8 \pm 7.6$ & 0.835 \\
\hline Smoking status & & & 0.132 \\
\hline Never & $15(68.2)$ & $19(86.4)$ & \\
\hline Ex-smoker & $7(31.8)$ & $2(9.1)$ & \\
\hline Current smoker & o & $1(4.5)$ & \\
\hline \multicolumn{4}{|l|}{ Concomitant allergic disease } \\
\hline Perennial allergic rhinitis & $19(86.3)$ & $18(81.8)$ & 0.265 \\
\hline Allergic conjunctivitis & $6(27.2)$ & $6(27.2)$ & 1.000 \\
\hline Urticaria & $4(18.2)$ & $9(40.9)$ & 0.292 \\
\hline Blood white blood cell counts, $\mathrm{K} / \mu \mathrm{L}$ & $8.0 \pm 2.6$ & $8.9 \pm 5.2$ & 0.489 \\
\hline Blood eosinophils, \% & $5 \cdot 5 \pm 4 \cdot 5$ & $5 \cdot 7 \pm 10.8$ & 0.951 \\
\hline Total IgE, IU/mL & $270.5 \pm 187.1$ & $153.4 \pm 11.23$ & 0.017 \\
\hline \multicolumn{4}{|l|}{ Pulmonary function test } \\
\hline $\mathrm{FEV} 1, \mathrm{~mL}$ & $1,876.8 \pm 118.5$ & $1,702.3 \pm 109.6$ & 0.286 \\
\hline $\mathrm{FEV} 1 \%$ & $66.9 \pm 2.3$ & $63.0 \pm 3.0$ & 0.307 \\
\hline \multicolumn{4}{|l|}{ Allergens } \\
\hline Perennial aeroallergens & $22(100)$ & $22(100)$ & 1.000 \\
\hline Seasonal aeroallergens & $9(40.9)$ & $7(31.8)$ & 0.901 \\
\hline \multicolumn{4}{|l|}{ Asthma clinical symptoms } \\
\hline Morning symptoms & & & 0.002 \\
\hline No symptoms at all; unrestricted activity & $5(22.7)$ & $16(72.7)$ & \\
\hline Symptoms caused little or no discomfort; unrestricted activity & $4(18.2)$ & $1(4 \cdot 5)$ & \\
\hline $\begin{array}{l}\text { Symptoms caused some discomfort; sometimes limiting } \\
\text { strenuous activity }\end{array}$ & $11(50.0)$ & $3(13.6)$ & \\
\hline $\begin{array}{l}\text { Symptoms caused moderate discomfort and at limited } \\
\text { routine activity }\end{array}$ & o & $1(4 \cdot 5)$ & \\
\hline $\begin{array}{l}\text { Symptoms occurred at rest, caused marked discomfort, and } \\
\text { usually limited routine activity }\end{array}$ & o & $1(0.5)$ & \\
\hline Night time symptoms & & & 0.049 \\
\hline Patient did not wake up & $10(45 \cdot 5)$ & $17(77 \cdot 3)$ & \\
\hline Patient awoke once, but did not use rescue medication & $9(40.9)$ & $3(13 \cdot 6)$ & \\
\hline $\begin{array}{l}\text { Patient awoke once, but their rescue medication controlled } \\
\text { the symptoms }\end{array}$ & $3(13.6)$ & $1(4 \cdot 5)$ & \\
\hline $\begin{array}{l}\text { Patient awoke more than once, but their rescue medication } \\
\text { controlled the symptoms }\end{array}$ & o & $1(4 \cdot 5)$ & \\
\hline $\begin{array}{l}\text { Patient had difficulty sleeping even though he/she used } \\
\text { rescue medication }\end{array}$ & o & o & \\
\hline Mean omalizumab dose per month, mg & $409.1 \pm 191.9$ & $283.0 \pm 166.8$ & 0.025 \\
\hline
\end{tabular}

Values are presented as number (\%) or mean \pm standard deviation.

KAQLQ, the Quality of Life Questionnaire for Adult Korean Asthmatics; IgE, immunoglobulin E; FEV1, forced expiratory volume in 1 second; $\mathrm{FEV} 1 \%$, forced expiratory volume in 1 second \% predicted. 
studies, the average AQLQ score increased by 0.7 and 1.0 points, respectively. In the studies by Bousquet et al. [18] and Busse et al. [13], the proportion of patients with an average improvement in AQLQ score of at least 0.5 points was more than $60 \%$, whereas the result obtained in our study was lower. The total IgE and $\mathrm{FEV}_{1} \%$ of the patients in this study were similar to those reported in the above studies. Further research is needed to determine whether the reason for the improvement in the quality of life that did not meet expectations was age or ethnic differences. In this study, $78.6 \%$ of the patients were "favorable" in GETE, as evaluated by the doctors. This was higher than that reported in the INNOVATE study [17] and the study by Buhl et al. [11], at 60.5\% and $59 \%$, respectively. Since the current study is an open clinical study, there is a possibility that the investigators' prejudice that the drug will be effective influenced the evaluation. The next Steps Toward personalised care: EvaLuating responders to XoLAIR treatment in patients with severe allergic asthma (STELLAIR) study a recent retrospective real-world evidence study, showed that the favorable group was $67.2 \%$ in adults and $77.2 \%$ in adolescents, showing results relatively similar to those obtained in this study [33]. In the K-ACT, in which patients evaluate their own asthma control, the partly controlled group or controlled group was only $40.9 \%$ before omalizumab treatment, but it rose to more than $70 \%$ after 16 weeks of treatment, similar to that reported in other studies $[12,13,17,18]$. Consistent with the results of other studies, pulmonary function improved from 4 weeks after the start of treatment and was sufficiently improved and maintained at 12 to 16 weeks [12,17]. In this study, there was no change in the mean daily dose of OCS maintenance therapy during the omalizumab treatment period. However, the amount of oral steroids used as rescue medication decreased significantly, which suggests that additional treatment with omalizumab reduced the exacerbation of asthma.

Asthma is a very heterogeneous disease that is divided into several clusters according to characteristics such as treatment response and prognosis because its cause or pathogenesis is complex, and the effects of the same drug can be observed differently. Omalizumab also showed various effects in a similar severe perennial allergic asthma patient group [21]. Previous studies have shown that omalizumab is effective in only $60 \%$ to $70 \%$ of patients with severe asthma [11,34]. Furthermore, it is still unclear how long omalizumab should be used [35]. Therefore, it is necessary to secure an index that can predict treatment response.

In this study, the baseline total IgE was significantly higher in the improved group than in the non-improved group from the KAQLQ; accordingly, the amount of omalizumab used was also higher. In addition, in the improved group, the day and night symptoms of asthma were more severe. Thus, the factors predicting the omalizumab response in Koreans with severe asthma are high baseline total IgE values and severe asthma symptoms. In this study, FEV1 improved immediately after 1 month of omalizumab administration and was maintained during the treatment period. This result suggests that the improvement in pulmonary function at the initial stage of omalizumab use is a predictor of omalizumab response. If pulmonary function does not improve within 3 to 4 months from the initial use of omalizumab, it may be stopped early, and other biologics may be considered. Bousquet et al. [35] conducted a study in 2011 and reported that GETE is an accurate predictor of a response to omalizumab. However, in this study, it was confirmed that the improved group as per the KAQLQ had a significantly increased FEV $1 \%$ at week 24 compared to that in the non-improved group. These results were not observed in the GETE. Therefore, KAQLQ can be considered a parameter to determine the effectiveness of omalizumab and whether to continue its administration in Korean patients.

The incidence of AEs upon omalizumab administration was approximately $70 \%$ in the INNOVATE study, but it was $30 \%$ to $40 \%$ in the study by Buhl et al. [11], which is similar to the $37.3 \%$ obtained in the present study. The ADR incidence in this study (5.9\%) was similar to that reported in the INNOVATE study (4.9\%) and by Buhl et al. (3.5\%) [11,17]. In this study, anaphylaxis, the most dangerous side effect of omalizumab, did not occur; only one case of eosinophilia was reported, in which the eosinophil count returned to the normal range after treatment discontinuation. Adverse reactions to omalizumab were also not considered to be more frequent or severe in Korean patients, and it appears that omalizumab can be used safely in the Korean population.

The limitations of this study are that there was no control group, it was conducted as an open test, and oth- 
er biological markers such as fractional exhaled nitric oxide were not measured concurrently. However, this study was the first to prospectively evaluate the effect of omalizumab in Korean patients with severe allergic asthma, and it is believed that it was sufficient to determine the effectiveness and safety of omalizumab in these patients.

Various biologics have been developed recently; this study confirmed the effectiveness and safety of omalizumab in Korean patients with severe allergic asthma. However, because omalizumab is not effective in all patients with allergic type 2 severe asthma, it is recommended to consider add-on omalizumab therapy in patients with high baseline total IgE levels and severe asthma symptoms and to evaluate the effect of omalizumab using the pulmonary function or KAQLQ score within 3 to 4 months after omalizumab treatment to determine whether to continue treatment.

\section{KEY MESSAGE}

1. In Korean patients with severe allergic asthma, additional treatment with omalizumab improved the quality of life, including asthma symptoms and lung function.

2. High total immunoglobulin E levels and severe asthma symptoms can be predictors of the positive effects of additional omalizumab treatment.

3. The effect of omalizumab should be re-evaluated after 3 to 4 months of treatment by checking the improvement of forced expiratory volume in 1 second \% predicted (FEV1\%) or the Quality of Life Questionnaire for Adult Korean Asthmatics (KAQLQ) to determine whether to continue omalizumab treatment.

\section{Conflict of Interest}

This study was supported by Novartis Pharmaceuticals.

\section{REFERENCES}

1. Global Initiative for Asthma (GINA). Global strategy for asthma management and prevention 2019 [Internet].
Fontana (WI): Global Initiative for Asthma; 2019 [cited 2021 May 12]. Available from: www.ginasthma.org.

2. Chung KF, Wenzel SE, Brozek JL, et al. International ERS/ ATS guidelines on definition, evaluation and treatment of severe asthma. Eur Respir J 2014;43:343-373.

3. Hekking PP, Wener RR, Amelink M, Zwinderman AH, Bouvy ML, Bel EH. The prevalence of severe refractory asthma. J Allergy Clin Immunol 2015;135:896-902.

4. Sadatsafavi M, Lynd L, Marra C, et al. Direct health care costs associated with asthma in British Columbia. Can Respir J 2010;17:74-80.

5. Lee E, Kim A, Ye YM, Choi SE, Park HS. Increasing prevalence and mortality of asthma with age in Korea, 20022015: a nationwide, population-based study. Allergy Asthma Immunol Res 2020;12:467-484.

6. McGregor MC, Krings JG, Nair P, Castro M. Role of biologics in asthma. Am J Respir Crit Care Med 2019;199:433445 .

7. Fajt ML, Wenzel SE. Development of new therapies for severe asthma. Allergy Asthma Immunol Res 2017;9:3-14.

8. Park HS, Lee SH, Lee SY, et al. Efficacy and safety of benralizumab for Korean patients with severe, uncontrolled eosinophilic asthma. Allergy Asthma Immunol Res 2019;11:508-518.

9. Easthope S, Jarvis B. Omalizumab. Drugs 2001;61:253-26o.

10. Buhl R, Soler M, Matz J, et al. Omalizumab provides longterm control in patients with moderate-to-severe allergic asthma. Eur Respir J 2002;20:73-78.

11. Buhl R, Hanf G, Soler M, et al. The anti-IgE antibody omalizumab improves asthma-related quality of life in patients with allergic asthma. Eur Respir J 2002;20:10881094.

12. Bousquet J, Rabe K, Humbert M, et al. Predicting and evaluating response to omalizumab in patients with severe allergic asthma. Respir Med 2007;101:1483-1492.

13. Busse WW, Massanari M, Kianifard F, Geba GP. Effect of omalizumab on the need for rescue systemic corticosteroid treatment in patients with moderate-to-severe persistent IgE-mediated allergic asthma: a pooled analysis. Curr Med Res Opin 2007;23:2379-2386.

14. Costello RW, Long DA, Gaine S, Mc Donnell T, Gilmartin JJ, Lane SJ. Therapy with omalizumab for patients with severe allergic asthma improves asthma control and reduces overall healthcare costs. Ir J Med Sci 2011;180:637641.

15. Hanania NA, Alpan O, Hamilos DL, et al. Omalizumab 
in severe allergic asthma inadequately controlled with standard therapy: a randomized trial. Ann Intern Med 2011;154:573-582.

16. Barnes N, Menzies-Gow A, Mansur AH, et al. Effectiveness of omalizumab in severe allergic asthma: a retrospective UK real-world study. J Asthma 2013;50:529-536.

17. Humbert M, Beasley R, Ayres J, et al. Benefits of omalizumab as add-on therapy in patients with severe persistent asthma who are inadequately controlled despite best available therapy (GINA 2002 step 4 treatment): INNOVATE. Allergy 2005;60:309-316.

18. Bousquet J, Wenzel S, Holgate S, Lumry W, Freeman $\mathrm{P}$, Fox H. Predicting response to omalizumab, an anti-IgE antibody, in patients with allergic asthma. Chest 2004;125:1378-1386.

19. Kim MH, Kim SH, Park SY, et al. Characteristics of adult severe refractory asthma in Korea analyzed from the severe asthma registry. Allergy Asthma Immunol Res 2019;11:43-54.

20. Lee JH, Lee HY, Jung CG, et al. Therapeutic effect of omalizumab in severe asthma: a real-world study in Korea. Allergy Asthma Immunol Res 2018;10:121-130.

21. Hanania NA, Wenzel S, Rosen K, et al. Exploring the effects of omalizumab in allergic asthma: an analysis of biomarkers in the EXTRA study. Am J Respir Crit Care Med 2013;187:804-11.

22. Park JW, Cho YS, Lee SY, et al. Multi-center study for the utilization of quality of life questionnaire for adult Korean asthmatics (QLQAKA). Korean J Asthma Allergy Clin Immunol 2000;20:467-480.

23. Busse WW. Biological treatments for severe asthma: a major advance in asthma care. Allergol Int 2019;68:158166.

24. Pavord ID, Hilvering B, Shrimanker R. Emerging biologics in severe asthma. Immunol Allergy Clin North Am 2016;36:609-623.

25. Cho YS, Oh YM. Dilemma of asthma treatment in mild patients. Tuberc Respir Dis (Seoul) 2019;82:190-193.

26. Agache I, Cojanu C, Laculiceanu A, Rogozea L. Critical points on the use of biologicals in allergic diseases and asthma. Allergy Asthma Immunol Res 2020;12:24-41.

27. Godar M, Blanchetot C, de Haard H, Lambrecht BN, Brusselle G. Personalized medicine with biologics for severe type 2 asthma: current status and future prospects. MAbs 2018;10:34-45.

28. Dreher M, Muller T. Add-on therapy for symptomatic asthma despite long-acting beta-agonists/inhaled corticosteroid. Tuberc Respir Dis (Seoul) 2018;81:1-5.

29. de Llano LP, Vennera Mdel C, Alvarez FJ, et al. Effects of omalizumab in non-atopic asthma: results from a Spanish multicenter registry. J Asthma 2013;50:296-301.

30. Garcia G, Magnan A, Chiron R, et al. A proof-of-concept, randomized, controlled trial of omalizumab in patients with severe, difficult-to-control, nonatopic asthma. Chest 2013;144:411-419.

31. Casale TB, Chipps BE, Rosen K, et al. Response to omalizumab using patient enrichment criteria from trials of novel biologics in asthma. Allergy 2018;73:490-497.

32. Katsaounou P, Buhl R, Brusselle G, et al. Omalizumab as alternative to chronic use of oral corticosteroids in severe asthma. Respir Med 2019;150:51-62.

33. Humbert M, Taille C, Mala L, et al. Omalizumab effectiveness in patients with severe allergic asthma according to blood eosinophil count: the STELLAIR study. Eur Respir J 2018;51:1702523.

34. Pelaia C, Calabrese C, Terracciano R, de Blasio F, Vatrella A, Pelaia G. Omalizumab, the first available antibody for biological treatment of severe asthma: more than a decade of real-life effectiveness. Ther Adv Respir Dis 2018;12:1753466618810192.

35. Bousquet J, Siergiejko Z, Swiebocka E, et al. Persistency of response to omalizumab therapy in severe allergic (IgE-mediated) asthma. Allergy 2011;66:671-678. 